\title{
Electrochemical Nitrogen Reduction Reaction on Ruthenium
}

\author{
Yao Yao ${ }^{\mathrm{a}, \mathrm{b}}$, Haijiang Wang c,d,e, Xiao-zi Yuan ${ }^{\mathrm{f}}$, Hui Li ${ }^{*}$, a,d,e , Minhua Shao *, b \\ a Department of Materials Science and Engineering, Southern University of Science and Technology, \\ 1088 Xueyuan Blvd, Nanshan District, Shenzhen, Guangdong 518055, China \\ ${ }^{b}$ Department of Chemical and Biological Engineering, The Hong Kong University of Science and \\ Technology, Clear Water Bay, Kowloon, Hong Kong \\ ${ }^{c}$ Department of Mechanical and Energy Engineering, Southern University of Science and Technology, \\ 1088 Xueyuan Blvd, Nanshan District, Shenzhen, Guangdong 518055, China \\ ${ }^{d}$ Shenzhen Key Laboratory of Hydrogen Energy, Southern University of Science and Technology, 1088 \\ Xueyuan Blvd, Nanshan District, Shenzhen, Guangdong 518055, China \\ ${ }^{e}$ Guangdong Provincial Key Laboratory of Energy Materials for Electric Power, Southern University of \\ Science and Technology, 1088 Xueyuan Blvd, Nanshan District, Shenzhen, Guangdong 518055, China \\ ${ }^{f}$ National Research Council Canada, Vancouver, BC, V6T 1W5, Canada
}

Correspondence to: hui.li@sustc.edu.cn;

kemshao@ust.hk 


\section{Table of Contents}

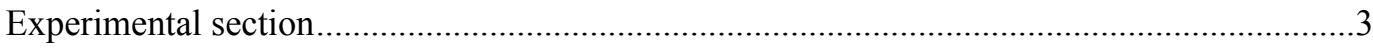

$\mathrm{CV}$ of the $\mathrm{Ru}$ thin-film in an Ar-saturated $\mathrm{HClO}_{4}$ electrolyte ..............................................

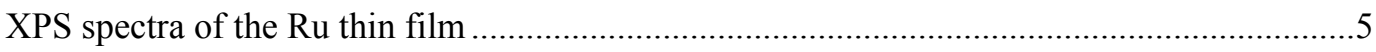

Subtractive infrared spectroscopy in a $\mathrm{N}_{2}$ - and an $\mathrm{Ar}$ - saturated $\mathrm{HClO}_{4}$ electrolyte .................6

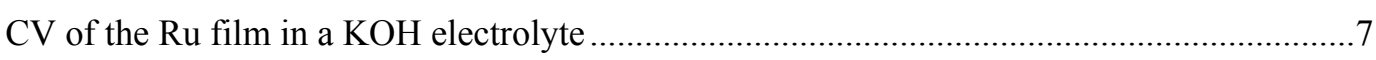

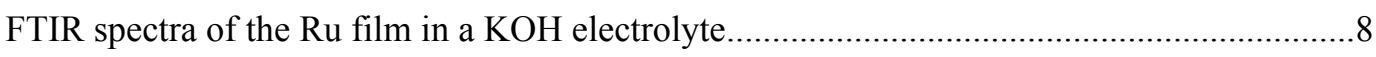

Subtractive infrared spectroscopy in a $\mathrm{N}_{2}$ - and an $\mathrm{Ar}$ - saturated $\mathrm{KOH}$ electrolyte ...................9

Current density - time curves of Ru thin film .................................................................... 10 


\section{Experimental section}

Synthesis of the Thin-Film Ruthenium Electrode. An Au thin film was deposited on the Si prism using the same chemical process as described specifically in a previous publication. ${ }^{1}$ The Si prism ( $20 \mathrm{~mm}$ in diameter, MTI Corp.) surface was polished with $\mathrm{Al}_{2} \mathrm{O}_{3}$ powder and cleaned in water with sonication. Then it was soaked in a piranha solution (3:1 volumetric ratio of $98 \% \mathrm{H}_{2} \mathrm{SO}_{4}$ (Aldrich) and $30 \% \mathrm{H}_{2} \mathrm{O}_{2}$ (Aldrich)) for $2 \mathrm{~h}$. The reflection plane was impregnated by $40 \% \mathrm{NH}_{4} \mathrm{~F}$ (Aldrich) for $90 \mathrm{~s}$, followed by an immersion in a mixture of $4 \mathrm{~mL}$ of Au plating solution ${ }^{2}$ and $50 \mu \mathrm{L}$ of $50 \% \mathrm{HF}$ solution (Aldrich) at $55^{\circ} \mathrm{C}$ for $5 \mathrm{~min}$. After the Au thin film was synthesized, the Ru thin film was galvanostatically electrodeposited on the Au film in a plating solution consisting of $1 \mathrm{mM} \mathrm{RuCl} 3$ (Aldrich) and $0.1 \mathrm{M} \mathrm{HClO}_{4}$ (Aladdin) at room temperature. The deposition current and duration were $1 \mathrm{~mA}$ and $180 \mathrm{~s}$, respectively.

The Ru thin film supported on the Si prism was employed as the working electrode (WE), with a geometrical surface area of $1.13 \mathrm{~cm}^{2}$. A Pt foil was used as the counter electrode. A $\mathrm{Hg} / \mathrm{HgO}$ and $\mathrm{Ag} / \mathrm{AgCl}$ electrodes were used as reference electrodes in alkaline and acidic electrolytes, respectively. The supporting electrolyte used in all measurements were $0.1 \mathrm{M} \mathrm{HClO}_{4}$ (Aladdin) and $0.1 \mathrm{M} \mathrm{KOH}\left(99.99 \%\right.$, Aladdin), constantly purged with $\mathrm{N}_{2}$ or $\operatorname{Ar}$ (5N, Air Products and Chemicals (Shenzhen), Inc.) during the experiment. All potentials in this study were referred to the reversible hydrogen electrode (RHE) scale. The electrochemical characterization was performed with a $\mathrm{CHI}$ 760 E electrochemical workstation.

Electrochemical SERIAS Measurements. The cell for SERIAS measurements in this study was the same as reported earlier. ${ }^{3}$ Before the experiment, the Ru film was cleaned by continuously scanning the potential from 0.05 to $0.8 \mathrm{~V}$ for 20 cycles in $0.1 \mathrm{M} \mathrm{HClO}_{4}$. The electrode was then scanned between 0.4 and $-0.4 \mathrm{~V}$ at a scan rate of $2.5 \mathrm{mV} \mathrm{s}^{-1}$ in Ar or $\mathrm{N}_{2}$-saturated electrolytes. Meanwhile, IR spectra were collected with a time resolution of $10 \mathrm{~s}$ per spectrum at a spectral resolution of $4 \mathrm{~cm}^{-1}$. All spectra were presented in absorbance, $A=-\log \left(R / R_{0}\right)$, where $R$ is the reflectance of the sample spectrum and $\mathrm{R}_{0}$ is the background spectrum. A Nicolet iS50 FTIR spectrometer was employed for the SERIAS measurements. 
$\mathrm{CV}$ of the $\mathrm{Ru}$ thin-film in an Ar-saturated $\mathrm{HClO}_{4}$ electrolyte

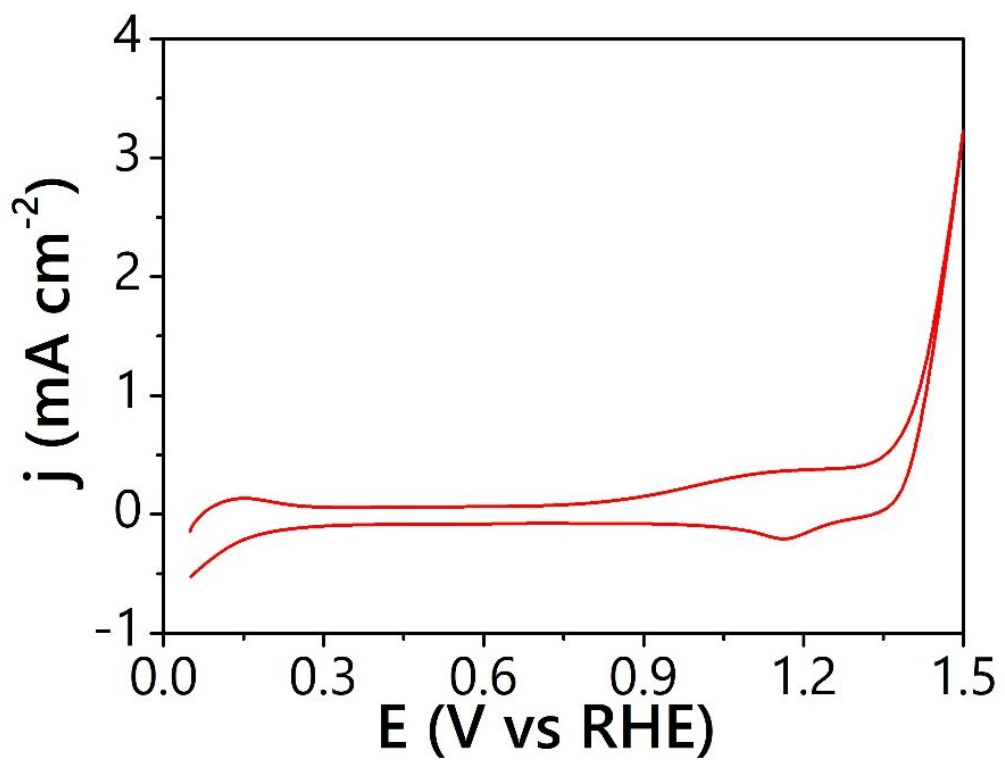

Figure S1. (a) The cyclic voltammograms of the Ru thin-film deposited on a Si prism in an Arsaturated $0.1 \mathrm{M} \mathrm{HClO}_{4}$ aqueous solution over a potential range of $0.05 \mathrm{~V}$ to $1.5 \mathrm{~V}$. Potential scan rate: $50 \mathrm{mV} \mathrm{s}^{-1}$. 
XPS spectra of the Ru thin film
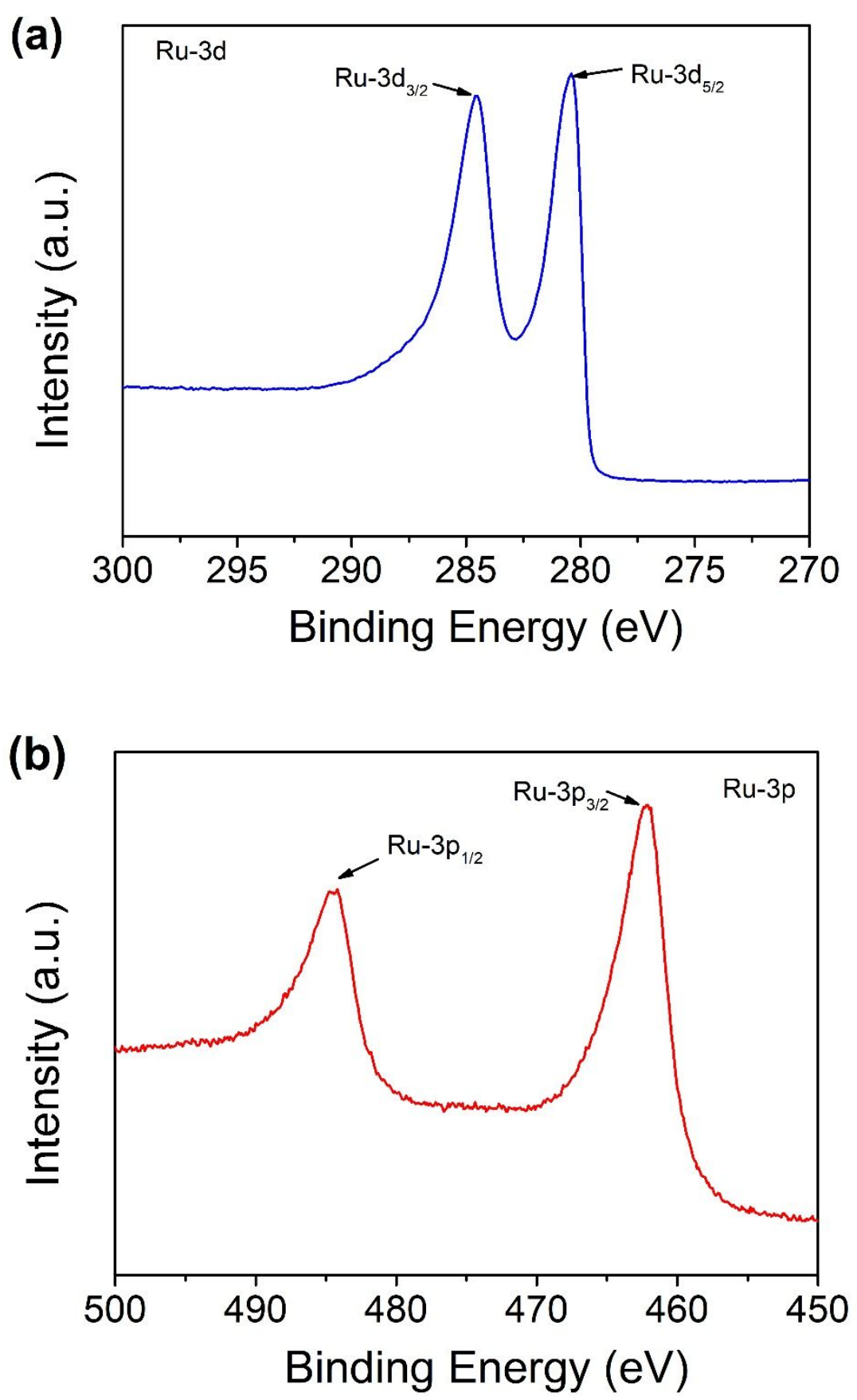

Figure S2. (a) $R u(3 d)$ and (b) $R u(3 p)$ XPS spectra for ruthenium thin film. 
Subtractive infrared spectroscopy in a $\mathrm{N}_{2^{-}}$and an Ar- saturated $\mathrm{HClO}_{4}$ electrolyte using Ru film - Si prism as window at open circuit potential

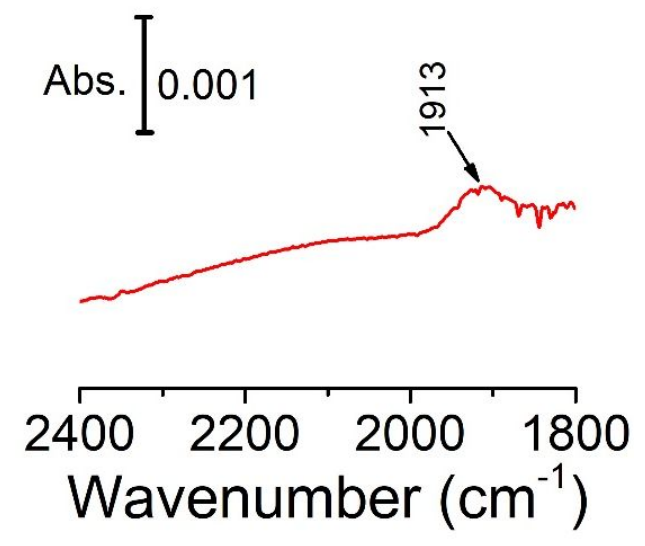

Figure S3. Subtractive Infrared spectroscopy in a $\mathrm{N}_{2}$ - and an $\mathrm{Ar}$ - saturated $\mathrm{HClO}_{4}$ electrolyte using $\mathrm{Ru}$ film - Si prism as window at open circuit potential. 


\section{$\mathrm{CV}$ of the Ru film in a KOH electrolyte}

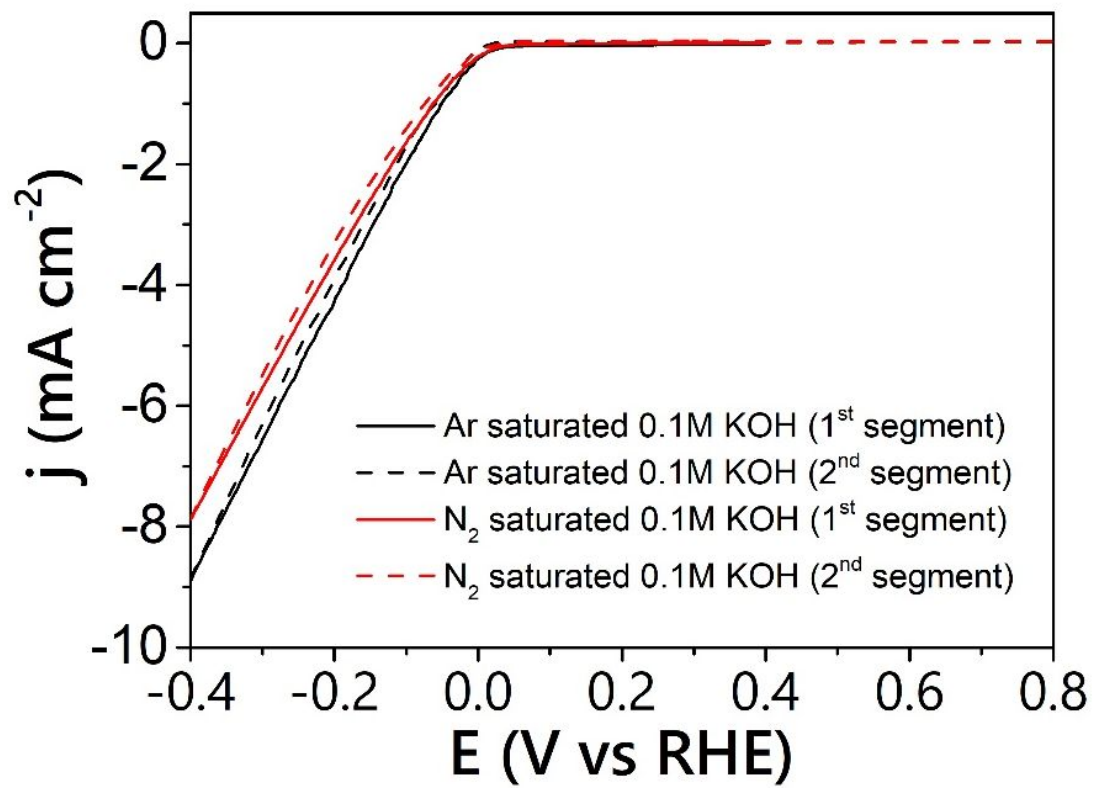

Figure S4. Cyclic voltammograms of a $\mathrm{Ru}$ film electrode in an Ar-saturated (black line) and a $\mathrm{N}_{2}$ saturated (red line) $0.1 \mathrm{M} \mathrm{KOH}$ aqueous solution. $\mathrm{An} \mathrm{Hg} / \mathrm{HgO}$ electrode was used as the reference. Potential scan rate: $2.5 \mathrm{mV} \mathrm{s}^{-1}$. 
FTIR spectra of the Ru film in a KOH electrolyte

(a)

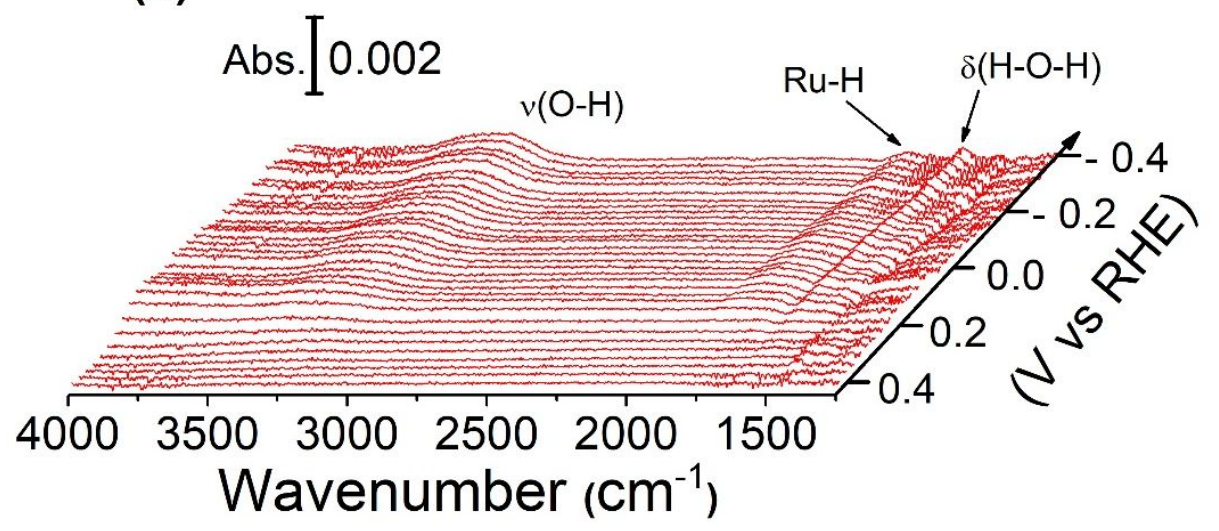

(b)

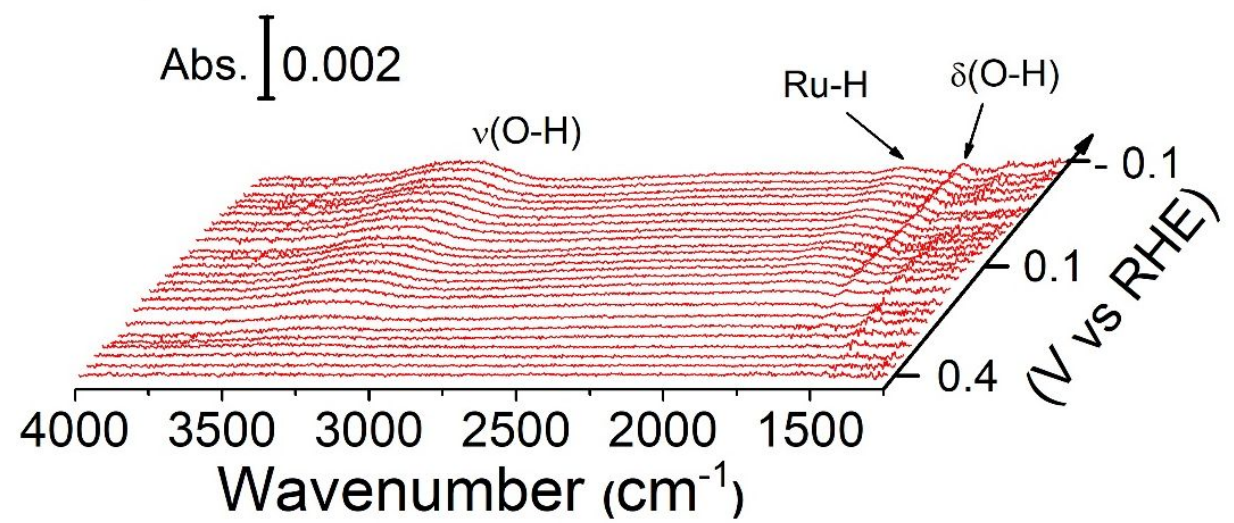

Figure S5. (a) FTIR spectra during the first segment from 0.4 to $-0.4 \mathrm{~V}$ on the Ru film electrode in a $\mathrm{N}_{2}$-saturated $0.1 \mathrm{M} \mathrm{KOH}$ solution. The reference spectrum was taken at $0.4 \mathrm{~V}$. (b) FTIR spectra during the first segment from 0.4 to $-0.4 \mathrm{~V}$ on the Ru film electrode in an Ar-saturated $0.1 \mathrm{M} \mathrm{KOH}$ solution. The reference spectrum was taken at $0.4 \mathrm{~V}$. 
Subtractive infrared spectroscopy in a $\mathrm{N}_{2}$ - and an Ar- saturated $\mathrm{KOH}$ electrolyte using Ru film - Si prism as window at open circuit potential

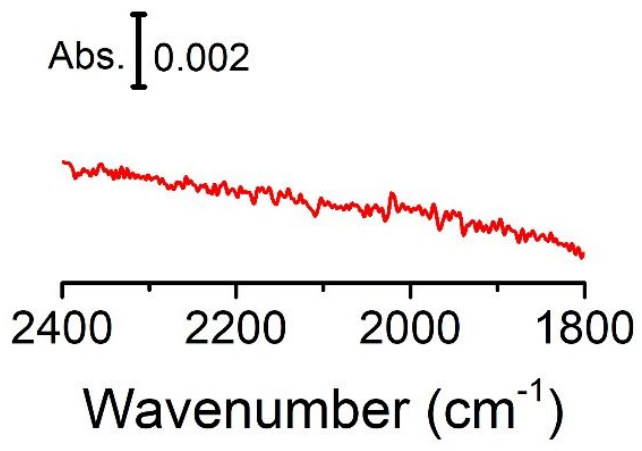

Figure S6. Subtractive Infrared spectroscopy in a $\mathrm{N}_{2}$ - and an Ar- saturated $\mathrm{KOH}$ electrolyte using $\mathrm{Ru}$ film - Si prism as window at open circuit potential. 


\section{Current density - time curves of Ru thin film}
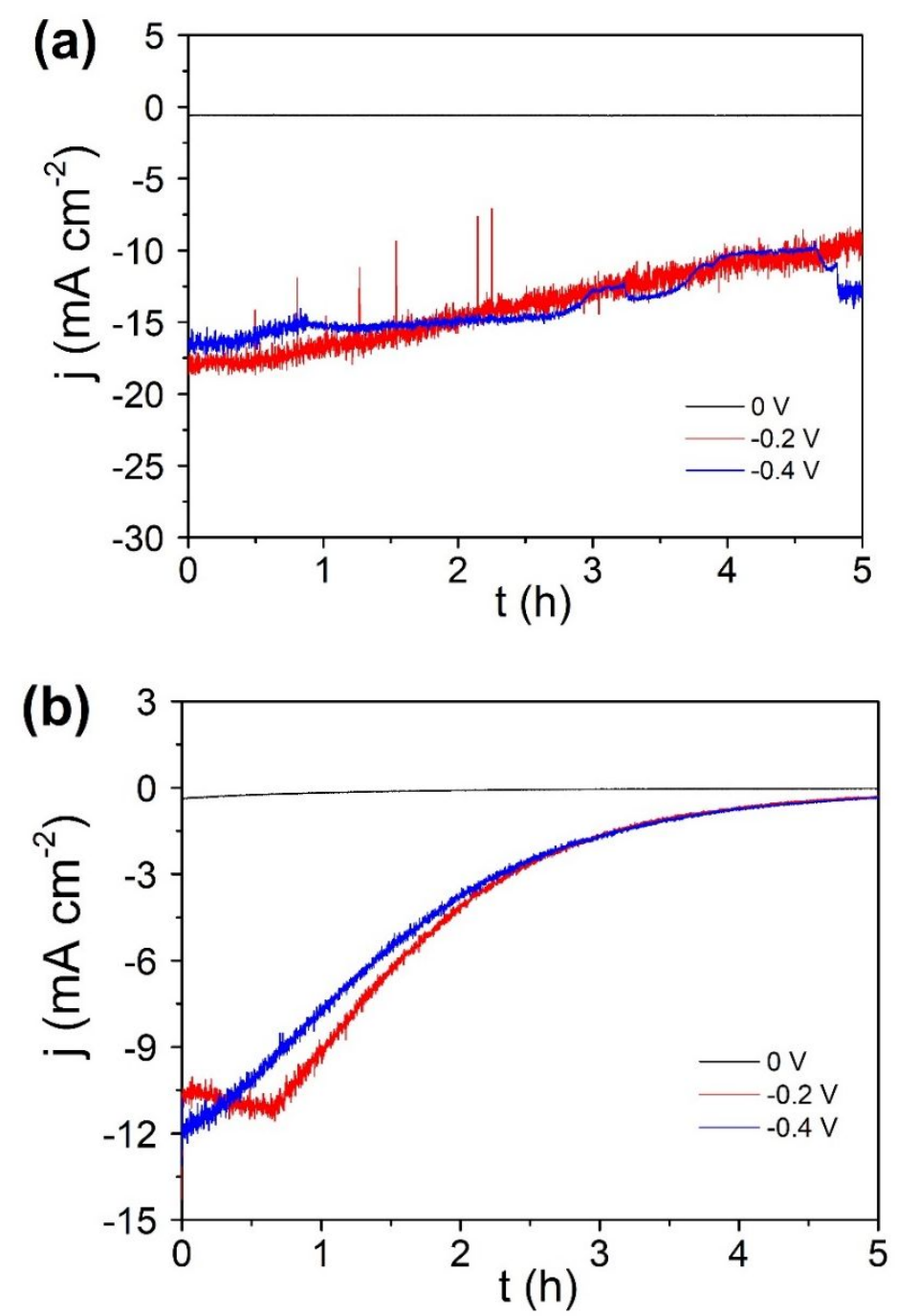

Figure S7. The current density - time curves of Ru thin film in (a) $\mathrm{N}_{2}$-saturated $0.1 \mathrm{M} \mathrm{HClO}_{4}$ and (b) $\mathrm{N}_{2}$-saturated $0.1 \mathrm{M} \mathrm{KOH}$ under ambient conditions.

\section{References}

(1) Yan, Y. G.; Li, Q. X.; Huo, S. J.; Ma, M.; Cai, W. B.; Osawa, M., J. Phys. Chem. B 2005, 109, 7900-7906.

(2) Miyake, H.; Ye, S.; Osawa, M., Electrochem. Commun 2002, 4, 973-977.

(3) Wang, H.; Jiang, B.; Zhao, T.-T.; Jiang, K.; Yang, Y.-Y.; Zhang, J.; Xie, Z.; Cai, W.-B., ACS 
Catal. 2017, 7, 2033-2041. 